\title{
Study of the Development of Cracks Accompanying Mechanical Loading of Solids
}

\author{
P. Koktavý* \\ Brno University of Technology, Faculty of Electrical Engineering and Communication Technologies, \\ Department of Physics, Brno, Czech Republic \\ *Corresponding author: koktavy@feec.vutbr.cz \\ B. Koktavý \\ Brno University of Technology, ${ }^{2}$ Faculty of Civil Engineering, Department of Physics, Brno, Czech Republic
}

DOI: $10.2478 / v 10158-010-0001-5$

\begin{abstract}
The formation of cracks in mechanically loaded insulators is accompanied by the generation of an electromagnetic field. Four basic processes of the crack's growth have been suggested based on the dipole model of a crack. A differential equation describing the transformation of the crack's primary parameters into a measurable electric signal has been derived for each of the four cases. Thus obtained theoretical curves have been compared with the experimental ones. Based on the comparison, some primary parameters of the crack have been determined.
\end{abstract}

KEY WORDS: Electromagnetic emission, crack, electric charge, model.

\section{INTRODUCTION}

The phenomenon of electromagnetic emission (EME) from solids (Koktavý, 2009) is based on the generation of an electromagnetic field arising from the mechanical excitation of the solid in question. This phenomenon may be triggered, for example, by external pressure, tensile, bending, shearing force, shocks, drilling, scratching, crushing, material fibre cutting, etc. At present, the EME waves are observed to be emitted from any material media: not only from solids, but also from liquids, gases, geological and biological objects. Measurement of electromagnetic emission signals can be employed in diagnosing these solids in the course of mechanical loading.

This paper presents a study of electromagnetic emission signals emitted from extren 500, an electrically non-conductive material. This material's structure is formed by a fibre-glass reinforcement bonded by a resin binder. Our specimens have been prepared in the form of rectangular blocks of dimensions (6 to 10) $\mathrm{mm} \times 50 \mathrm{~mm} \times 60 \mathrm{~mm}$.

\section{MODELS FOR THE GENERATION OF EME}

Although there are currently a number of experimental studies dealing with various aspects of the electromagnetic emission phenomenon, the physical origin of this phenomenon has not been satisfactorily accounted for until now. Several models based on the assumption that mechanical loading of electrically non-conducting solids results in non-uniform distribution of electric charges on the crack faces have been presented. Opposite sign charges 
occur on these crack faces, producing a time variable electric dipole or quadrupole, which in turn creates a source of EME emission. The fact that electric charges occur on the faces of a crack in the course of its formation has not been satisfactorily explained until now. The above-mentioned theory of EME generation has been submitted in many papers, for example in (Chatiašvili,1988), (Chatiašvili, 1991), (Šikula et al. 1996) and (Lokajíček \& Šikula,1996).

Another model for the EME generation has been put forward by Gershenzon et al (Gershenzon et al. 1987), who suppose that electric charges are generated on the top of the crack and, moreover, the crack faces are charged with opposite sign charges. If the crack grows in size, the dipole moment changes and EME is generated.

Other models are based on physical characteristics of the displacement of dislocations. In the case of a non-homogeneous distribution of dislocations, which is due to elastic-plastic transitions accompanying a compression, the movement of the dislocation is stopped suddenly and, consequently, conductivity electrons will generate EME [6]. Still other theories are based on the growth of the dislocation length which in turn results in the growth of the dipole moment associated with the dislocation in question and, consequently, electromagnetic radiation.

Our model of EME generation is based on the hypothesis that electric charges giving rise to an electric dipole or quadrupole, occur on the crack faces.

\section{CAPACITANCE SENSOR}

For laboratory measurements of the electromagnetic emission, one can take advantage of a capacitance sensor in the form of a parallel-plate capacitor whose dielectric is the mechanically loaded specimen [1], see Fig. 1. Here, $C$ is the capacitance of the pick-up capacitor; $\boldsymbol{E}$ is the intensity of the electric field in the space between the capacitor plates. The $C_{2} R_{1}$ circuit forms a low-pass filter, $C_{1}$ is the preamplifier input plus the cable capacity and $R_{1}$ is the equivalent resistance of the load resistance $R$ being connected in parallel to the input resistance of the pre-amplifier.

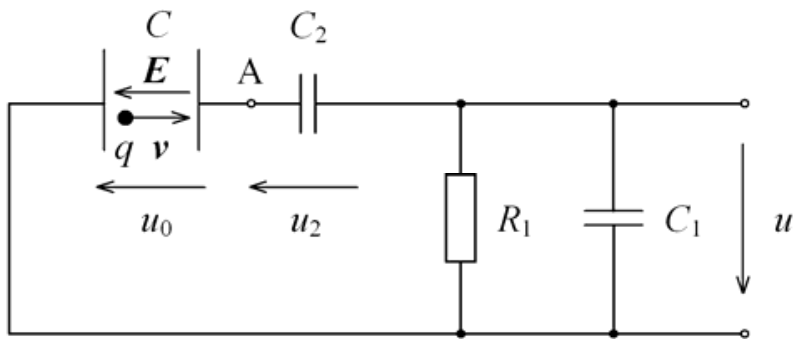

Figure 1: Capacitance sensor.

Let charges $q(t)$ a $-q(t)$ move in the space between the pick-up capacitor with velocities $v(t)$ and $-\boldsymbol{v}(t)$, respectively. Then a differential equation for the sensor output voltage $u$ holds:

$$
\frac{\mathrm{d} u}{\mathrm{~d} t}+\frac{u}{R_{1} C^{\prime}}=B q(t) v(t)
$$

where $B=2 \cos \alpha /\left(C^{\prime \prime} d\right), C^{\prime}=C_{1}+C C_{2} /\left(C+C_{2}\right), C^{\prime \prime}=C+C_{1}+C_{1} C / C_{2}, d$ is the specimen thickness and is an angle between $\boldsymbol{E}$ and $\boldsymbol{v}$. 
In our sensor, the capacitances are as follows: $C=18 \mathrm{pF}, C_{1}=18 \mathrm{pF}, C_{2}=120 \mathrm{pF}$ and the resistance $R_{1}=1.1 \mathrm{M} \Omega$. Then $C^{\prime}=34 \mathrm{pF}$ and $C^{\prime \prime}=39 \mathrm{pF}$. For the specimen thickness $d=10^{-2} \mathrm{~m}$ and the angle $=$, it holds $B=5.1 \times 10^{12} \mathrm{~F}^{-1} \cdot \mathrm{m}^{-1}$.

\section{CRACK FORMATION PROCESS}

The sensor output voltage $u(t)$ depends on the time-dependent charge $q(t)$ and on the face displacement $x(t)$ from the original position, where $2 x(t)$ is the crack width. The face movement velocity determines the face charge movement time rate. The crack formation process may be split into two phases. In the first stage, the crack unclenches and $q(t)$ and $x(t)$ are growing. In the second stage, which follows the crack unclenching, the charge may either be considered to be constant or falling exponentially in consequence of the material electrical conductivity, and the face velocity either zero or time variable. In this case, the faces can be considered to execute either periodical damped or aperiodically damped oscillations.

\section{MODEL A}

Let us assume the face charge and movement velocity to be constant. The solution of the differential equation (1) is of the form

$$
u(t)=B q v \tau\left[1-\mathrm{e}^{-\frac{t}{\tau}}\right]
$$

where the integration constant $K$ has been determined from the initial condition $u(0)=0$. If the process first phase terminates at the time $t_{\mathrm{m}}$, the sensor output voltage is $u\left(t_{\mathrm{m}}\right)=u_{\mathrm{m}}$ and the velocity $v=0$. The solution then is

$$
u(t)=u_{\mathrm{m}} \mathrm{e}^{-\frac{t-t_{\mathrm{m}}}{\tau}}
$$

The sensor output voltage versus time plot is shown in Fig. 2 (for $t_{\mathrm{m}}=3 \mu \mathrm{s}, B=5.1 \times$ $10^{12} \mathrm{~F}^{-1} \cdot \mathrm{m}^{-1}, \tau=37 \mu \mathrm{s}, q v=10^{-10} \mathrm{C} \cdot \mathrm{m} \cdot \mathrm{s}^{-1}, u_{\mathrm{m}}=1.48 \mathrm{mV}$ ).

As it holds

$$
u_{\mathrm{m}}=B q v \tau\left[1-\mathrm{e}^{-\frac{t_{\mathrm{m}}}{\tau}}\right]
$$

the time $t_{\mathrm{m}}$ and the charge times velocity product $q v$ can be determined.

In Fig. 3, experimental curves are best-fit-approximated by model A functions. On the basis of this approximation, parameters of this model can be subsequently determined. 
In this way, following quantities have been found out: $\tau=39.7 \mu \mathrm{s}, B q v \tau=0.0374 \mathrm{~V}$, $u_{\mathrm{m}}=0.904 \mathrm{mV}, t_{\mathrm{m}}=0.97 \mu \mathrm{s}$ (measured from the impulse starting point). From these data, the charge times face velocity product can be determined: $q v=1.85 \times 10^{-9} \mathrm{C} \cdot \mathrm{m} . \mathrm{s}^{-1}$.

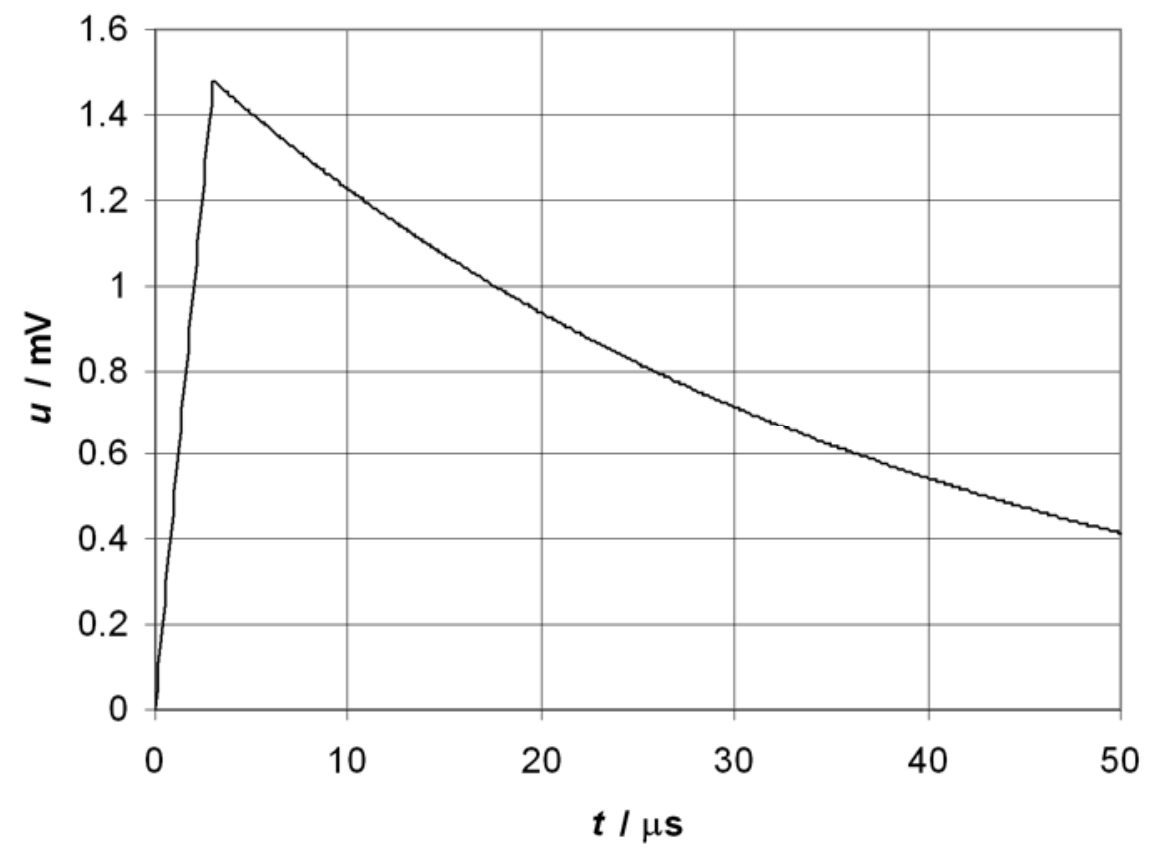

Figure 2: Theoretical sensor output voltage versus time plot, model A.

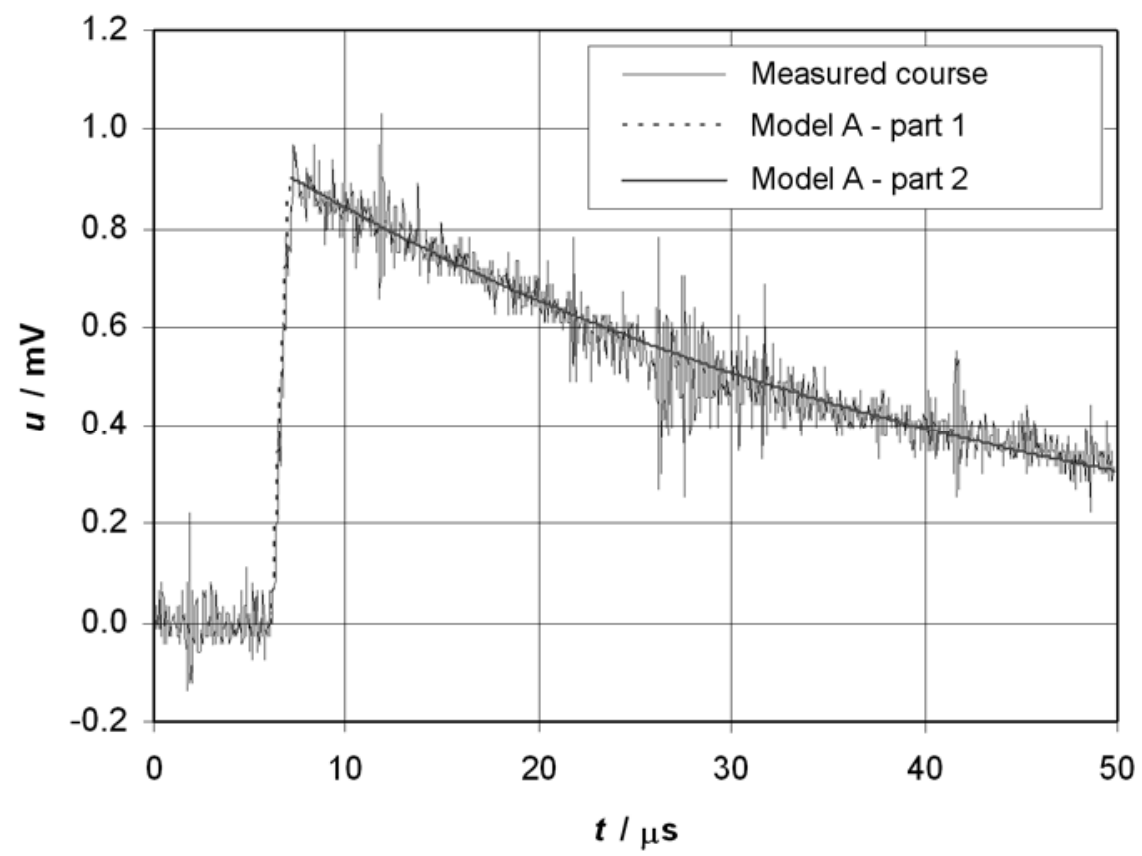

Figure 3: Comparison of experimental and theoretical time plots for model A, extren 68.028. 


\section{MODEL B}

Let the charge $q(t)$ and the face displacement $x(t)$ from the equilibrium position be

$$
\begin{aligned}
& q(t)=q_{0}\left(1-\mathrm{e}^{-\frac{t}{\tau_{q}}}\right), \\
& x(t)=x_{0}\left(1-\mathrm{e}^{-\frac{t}{\tau_{x}}}\right),
\end{aligned}
$$

where $\tau_{q}$ and $\tau_{x}$ are the time constants of the charge and face displacement. The crack face velocity then is

$$
v(t)=\frac{x_{0}}{\tau_{x}} \mathrm{e}^{-\frac{t}{\tau_{x}}}
$$

Equation (1) has the following solution:

$$
u(t)=\frac{B q_{0} x_{0}}{\tau_{x}}\left(\frac{1}{D} \mathrm{e}^{-\frac{t}{\tau_{x}}}-\frac{1}{E} \mathrm{e}^{-\left(\frac{1}{\tau_{q}}+\frac{1}{\tau_{x}}\right) t}+\frac{F}{E D} \mathrm{e}^{-\frac{t}{\tau}}\right)
$$

where $D=1 / \tau-1 / \tau_{x}, \quad E=1 / \tau-1 / \tau_{x}-1 / \tau_{q}, \quad F=1 / \tau_{q}$. The time plot of the quantity $u_{0}(t)=u(t) /\left(B q_{0} x_{0}\right)$ is shown in Fig. 4.

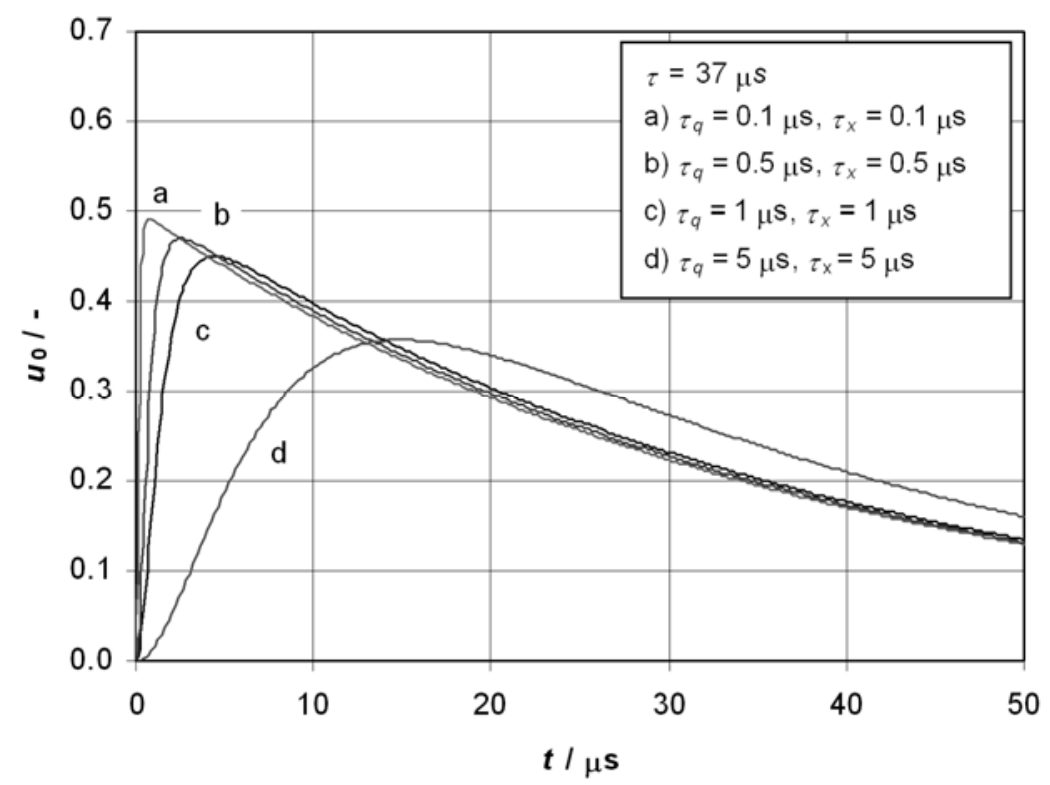

Figure 4: Theoretical time plot of the sensor normalized output voltage for model $B$ and different time constants $\tau_{q}$ a $\tau_{x}$. 
In models $\mathrm{A}, \mathrm{B}$, it is assumed that the magnitudes of $q(t)$ and $x(t)$ do not change any more after they have reached their maximum values (in the second stage of the process).

In Fig. 5, the experimental curve is best-fit-approximated by function (8). From this plot, following quantities have been read out: $\tau_{x}=4.66 \mu \mathrm{s}, \tau_{q}=0.847 \mu \mathrm{s}$ and $\tau=12.1 \mu \mathrm{s}$. It is seen that the experimental curve fits the theoretical one very well (corresponding to (8)).

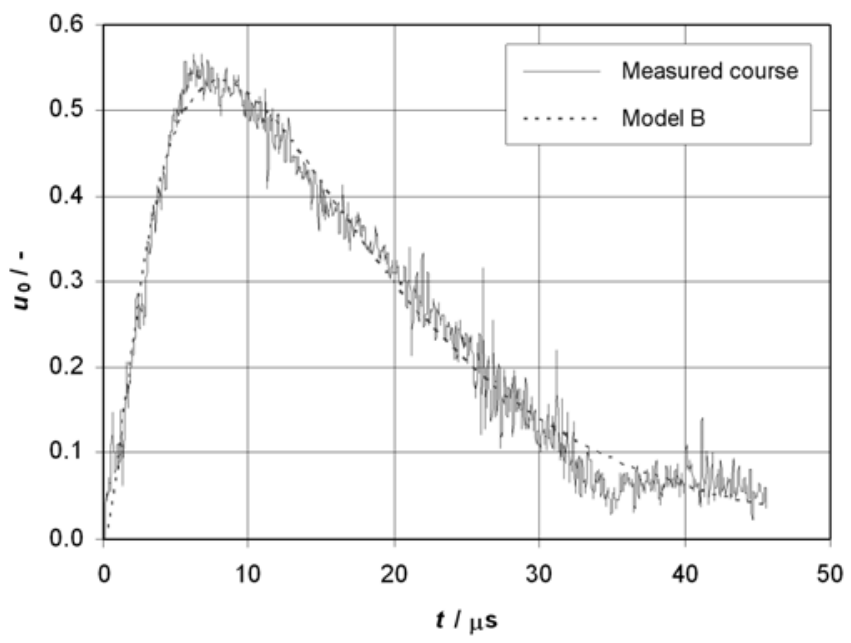

Figure 5: Comparison of experimental and theoretical time plots for model B, extren 61.097.

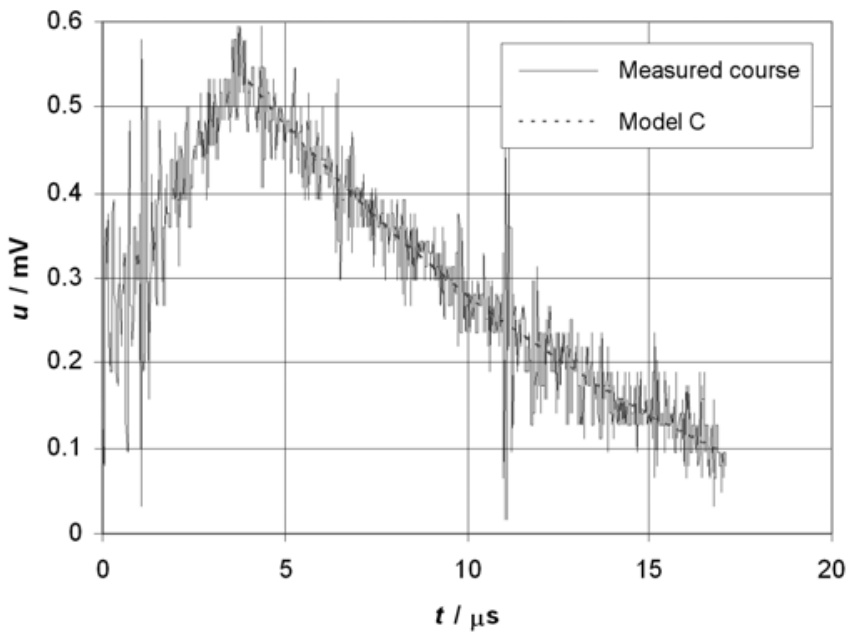

Figure 6: Comparison of experimental and theoretical time plots for model C, extren 58.050 .

\section{MODEL C}

After the crack unclenches at time $t_{\mathrm{m}}$, the face charge $q(t)$ and the face separation $x(t)$ either do not change (second stage of model A or B), or the crack faces execute damped oscillation and, possibly also, an electric charge relaxation takes place in consequence of the electric conductivity of the material which cannot be neglected. In the case of the face critically or supercritically damped oscillations, we may suppose

$$
\begin{gathered}
x(t)=x_{\mathrm{m}}-x_{0}\left(1-\mathrm{e}^{-\delta\left(t-t_{\mathrm{m}}\right)}\right), \\
q(t)=q_{\mathrm{m}} \mathrm{e}^{-\beta\left(t-t_{\mathrm{m}}\right)}
\end{gathered}
$$


where $x_{\mathrm{m}}$ is the face displacement at time $t_{\mathrm{m}}, x_{0}$ is the amplitude of the damped motion, $\delta$ is the mechanical damping coefficient, $1 / \beta$ is the time constant of the electric charge relaxation.

Now, equation (1) has the following solution

$$
u(t)=A \mathrm{e}^{-\gamma\left(t-t_{\mathrm{m}}\right)}+\left(u_{\mathrm{m}}-A\right) \mathrm{e}^{-\frac{t-t_{\mathrm{m}}}{\tau}}, \quad t \geq t_{\mathrm{m}},
$$

where $A=B x_{0} q_{\mathrm{m}} \delta \tau /(\gamma \tau-1)$ and $\gamma=\beta+\delta$.

The time plot of $u(t)$ is shown in Fig. 6 for $\tau=37.0 \mu \mathrm{s}, 1 / \gamma=17.1 \mu \mathrm{s}, A=1.17 \mathrm{mV}$, $u_{\mathrm{m}}=0.529 \mathrm{mV}$.

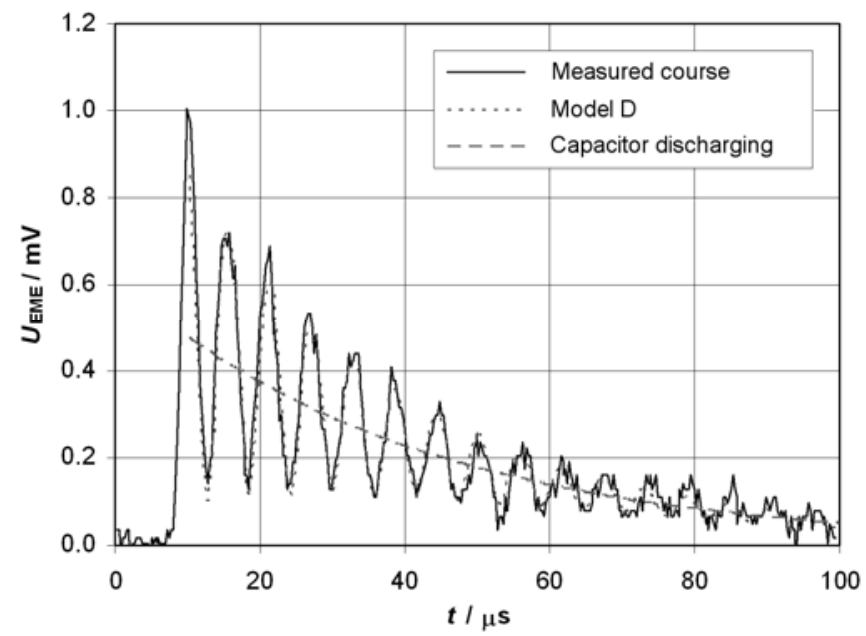

Figure 7: Comparison of experimental and theoretical time plots for model D, extren 52.023.

\section{MODEL D}

In the case of subcritically damped oscillations of the crack faces with angular frequency $\omega$ it holds

$$
x(t)=x_{\mathrm{m}}+x_{0} \mathrm{e}^{-\delta\left(t-t_{\mathrm{m}}\right)} \sin \left[\omega\left(t-t_{\mathrm{m}}\right)+\varphi_{0}\right],
$$

where $t_{\mathrm{m}}$ is the time at which the crack face displacement $x_{\mathrm{m}}$ is maximum, $\delta$ is the mechanical damping coefficient.

In this case, equation (1) has the following solution

$$
u(t)=U_{0} \mathrm{e}^{-\frac{t-t_{\mathrm{m}}}{\tau}}-\frac{B b x_{0} q_{\mathrm{m}} \mathrm{e}^{-\gamma\left(t-t_{\mathrm{m}}\right)}}{\sqrt{\omega^{2}+\omega_{0}^{2}}} \sin \left[\omega\left(t-t_{\mathrm{m}}\right)+\varphi_{0}+\varphi+\psi\right]
$$

where $U_{0}$ is an integration constant, $b=\left(\omega^{2}+\delta^{2}\right)^{1 / 2}, \operatorname{tg} \varphi=-\omega / \delta, \gamma=\beta+\delta, \omega_{0}=\gamma-1 / \tau$, $\operatorname{tg} \psi=\omega / \omega_{0}, 1 / \beta$ is the time constant of the electric charge relaxation.

The first term in (13) characterizes the discharging of a capacitor of a capacitance $C^{\prime}$ through a resistance $R_{1}$, the other term represents the response to the face charge oscillations. 
Fig. 7 shows the experimental time plot of an EME voltage for extren 52.023 (the first curve). Following parameters have been determined for this plot and model D: $\left(U_{0}=4.77 \times 10^{-4} \mathrm{~V}, \tau=40.1 \mu \mathrm{s}, \quad B b x_{0} q_{\mathrm{m}} /\left(\omega^{2}+\omega_{0}^{2}\right)^{1 / 2}=3.84 \times 10^{-4} \mathrm{~V}, \quad \gamma=3.99 \times\right.$ $\left.10^{4} \mathrm{~s}^{-1}, \omega=1.09 \times 10^{6} \mathrm{~s}^{-1}, \varphi_{0}+\varphi+\psi=-1.38\right)$. The second curve has been drawn using these quantities. The third curve represents the capacitor discharging transient.

\section{CONCLUSIONS}

Four models of EME signal generation in mechanically loaded composite materials have been put forward.

The simplest model, A, assumes the face charge and velocity to be constant. Although this is a heavy simplification, time plots corresponding to this model can be found in the signals being picked up.

Model B, which assumes both the charge and the crack face distance to follow an exponential law, appears very well suited for interpreting the measurement results.

Model C is well suited for the crack face damped oscillations after the crack unclenching.

Model D, which assumes quasi-harmonic oscillations of the crack faces after the crack unclenching, appears to be promising for the future from the viewpoint of the crack geometry studies. About $25 \%$ of experimental time plots fall into this model type.

The above mentioned models can be applied to diagnosing mechanically loaded electrically non-conducting solids.

\section{ACKNOWLEDGMENT}

This paper has been prepared under the subsidy of the Research Intent No. MSM 0021630503, which is currently being dealt with at the Faculty of Electrical Engineering and Communication Technologies of Brno University of Technology.

\section{REFERENCES}

Koktavý, P.: 2009. Experimental study of electromagnetic emission signals generated by crack generation in composite materials. Meas. Sci. Technol, vol. 20, 015704.

Chatiašvili, N. G.:1988. Vozmožnye mechanizmy elektromagnitnovo izlučenija pri razrušeniji kristalov i gornych porod. Geofizičeskij žurnal, vol. 10, pp. 45 - 53.

Chatiašvili, G.:1991. Elektromagnitnoje izlučenije pri deformacii i razrušeniji gornych porod i kristalov. AN Gruzii, Inst. geofiziki. "Mecniereba" Tbilisi.

Šikula, J., Koktavý, B., Vašina, P., Weber, Z., Kořenská, M., Lokajíček, T.:1996. Electromagnetic and Acoustic Emission from Solids. Proc. of 22nd European Conference on Acoustic Emission Testing, Aberdeen, UK.

Lokajíček, T., Šikula, J.:1996. Acoustic Emission and Electromagnetic Effects in Rocks. Progress in Acoustic Emission VIII, pp. 311 - 314.

Gershenzon, N., Gokhberg, M. Morgunov, V.: 1987. Sources of electromagnetic emissions preceding seismic events. Izv. Earth Phys, vol. 23, pp. 96 - 101. 